\title{
Sequence analysis proves clonal identity in five patients with typical and blastoid mantle cell lymphoma
}

\author{
C Cameron Yin, L Jeffrey Medeiros, Candy C Cromwell, Ashwini P Mehta, Pei Lin, \\ Rajyalakshmi Luthra and Lynne V Abruzzo \\ Department of Hematopathology, The University of Texas MD Anderson Cancer Center, Houston, TX, USA
}

\begin{abstract}
Mantle cell lymphoma (MCL) is typically composed of small irregular lymphoid cells. Blastoid variants, composed of lymphoblast-like (classic type) or large (pleomorphic type) cells, arise de novo or in patients with typical MCL. Although it has been assumed that blastoid variant represents histologic transformation of typical MCL, the clonal relationship between the two tumors has rarely been assessed at the molecular level. We identified five patients with typical MCL who subsequently developed the blastoid variant. There were two men and three women with a median age of 65 years (range, 34-70) at diagnosis of typical MCL involving lymph nodes. The median interval between typical and blastoid MCL was 36 months (range, 11-103). Subsequent blastoid variant MCL involved soft tissue (two), lymph node (one), ileum (one), or rectum (one). All typical and blastoid neoplasms were positive for CD20, cyclin D1, and monotypic surface immunoglobulin light chain, and all typical cases were positive for CD5. Two blastoid neoplasms lost CD5 expression, one of which aberrantly expressed CD10. Immunostaining for Ki-67 showed a median proliferative fraction of $20 \%$ in typical and $70 \%$ in blastoid neoplasms. Sequence analysis of the VDJ regions of the rearranged IgH allele proved clonal identity in each set of paired samples in all five patients. These results support the concept that blastoid MCL arising in patients with typical MCL represents histologic transformation of the original neoplastic clone.

Modern Pathology (2007) 20, 1-7. doi:10.1038/modpathol.3800716; published online 20 October 2006
\end{abstract}

Keywords: mantle cell lymphoma; blastoid; histologic transformation

Mantle cell lymphoma (MCL) is a distinct type of B-cell lymphoma characterized by the $\mathrm{t}(11 ; 14)(\mathrm{q} 13$; q32) and cyclin D1 overexpression. Histologically, MCL is typically composed of a monotonous population of small to medium-sized lymphoid cells with slightly irregular nuclear contours and a relatively low mitotic rate. Immunophenotypically, MCL expresses monotypic surface immunoglobulin, pan-B-cell antigens, and CD5, and is usually negative CD10 and CD23. ${ }^{1,2}$

A histologically more aggressive form of MCL, blastoid variant, also occurs, either de novo or in patients with typical MCL. Two types of blastoid MCL are described, consisting of either lymphoblast-like (classic type) or large (pleomorphic type) cells with a high proliferative fraction. ${ }^{3-6}$ In patients who have both typical and blastoid variant MCL,

Correspondence: Dr LV Abruzzo, MD, PhD, Department of Hematopathology, The University of Texas MD Anderson Cancer Center, 1515 Holcombe Blvd., Houston, TX 77030, USA.

E-mail: labruzzo@mdanderson.org

Received 23 August 2006; accepted 17 September 2006; published online 20 October 2006 either simultaneously or sequentially, the relationship between these neoplasms is not well studied. One might assume that both the typical and blastoid variant MCL are clonally related, analogous to low-grade follicular lymphoma and diffuse large B-cell lymphoma. However, in patients with chronic lymphocytic leukemia/small lymphocytic lymphoma (CLL/SLL) who develop diffuse large B-cell lymphoma, so-called Richter's syndrome, molecular genetic analysis indicates that the CLL/SLL and diffuse large B-cell lymphoma are clonally related in approximately $50 \%$ of cases. ${ }^{7,8}$ In our review of the literature, we have identified only three patients in which the clonal relationship between typical and blastoid MCL was assessed., ${ }^{9,10}$

We have reviewed the clinical, morphologic, and immunophenotypic features of five patients who presented with typical MCL and subsequently developed blastoid MCL. The clonal relationship of the five paired tumors, evaluated by DNA sequence analysis of the VDJ regions of the rearranged immunoglobulin heavy chain $(\operatorname{IgH})$ alleles, demonstrated identical sequences within each pair. 


\section{Materials and methods}

\section{Case Selection}

Five patients who presented with typical MCL and subsequently developed blastoid variant MCL were identified through a search of the files of the Department of Hematopathology, The University of Texas MD Anderson Cancer Center from January 1993 to June 2005. Clinical information was obtained by review of the medical records.

For all cases, Wright-Giemsa-stained peripheral blood and bone marrow aspirate smears, and hematoxylin and eosin (H\&E)-stained histologic sections of bone marrow aspirate clot and core biopsy specimens, lymph node, or other tissue biopsy specimens were reviewed. The diagnosis of MCL was based on morphologic and immunophenotypic findings according to the World Health Organization (WHO) classification criteria. ${ }^{11}$ The cases were classified as follows: (1) typical MCL, composed of a monotonous population of small to medium-sized lymphoid cells with irregular nuclear contours, moderately dispersed chromatin, inconspicuous nucleoli, scant cytoplasm, and a generally low-to-moderate mitotic rate; (2) classic blastoid MCL, composed of cells that resemble lymphoblasts, with dispersed chromatin and a high mitotic rate ( $>10$ mitotic figures per 10 high-power fields, and usually at least 20-30 mitotic figures per 10 high-power fields); (3) pleomorphic blastoid MCL, composed of a heterogeneous population of cells with large cleaved to oval nuclei, frequently prominent nucleoli, and pale cytoplasm. The diagnosis of MCL was further confirmed by immunophenotypic analysis, including immunohistochemical staining for cyclin D1.

\section{Immunophenotypic Analysis}

Immunohistochemical stains were performed using formalin-fixed, paraffin-embedded tissue sections, an avidin-biotin-peroxidase complex method, and an automated immunostainer (Ventana-Biotech, Tucson, AZ, USA). All tissue sections underwent heat-induced antigen retrieval. The antibodies were specific for CD5 (1:20, Labvision/Neomarker, Montreal, Quebec, Canada), CD20 (1:700, Dako, Carpinteria, CA, USA), immunoglobulin kappa and lambda light chains (1:20 000, Dako), Ki-67 (1:100, Dako), and cyclin D1 (1:40, Zymed Laboratories Inc., South San Francisco, CA, USA). The percentage of Ki-67 staining were reported as mean percentage of lowest and highest Ki-67-positive cells.

Immunophenotypic analysis was performed by flow cytometry according to standard methods on a FACScan instrument (BD Biosciences, San Jose, CA, USA) as described previously. ${ }^{12}$ The antibody panel included reagents specific for CD5, CD10, CD19, CD20, CD23, CD45, and surface immunoglobulin kappa and lambda light chains. All antibodies were purchased from BD Biosciences.

\section{Sequence Analysis of the IgH VDJ Region}

The IgH gene was assessed in all cases using DNA extracted from fixed, paraffin-embedded tissue sections with the QIAamp DNeasy Tissue Kit (Qiagen, Valencia, CA, USA) as described previously. ${ }^{13}$ For case 2, the typical and blastoid components were microdissected and analyzed separately. A polymerase chain reaction (PCR) assay was performed in a 9700 thermal cycler (PE/Applied Biosystems, Foster City, CA, USA) using consensus primers that anneal to the complementary framework II (FRII) (5'-TGG (A/G)TCCG(A/C/G)CAG(G/C)C(T/C)CC(A/C/G/T)GG$3^{\prime}$ ) or FRIII (5'-TCGGATCCACGGC(T/C)(C/G)TGTAT TACTGT-3') regions of the variable segments, and to a conserved $3^{\prime}$ region of JH segments ( $5^{\prime}$-AACTGCAG AGGAGACGGTGACC-3'). The reaction mix contained $1 \times$ PCR reaction buffer (PE/Applied Biosystems), $0.2 \mathrm{mM}$ of dNTPs, $0.4 \mu \mathrm{M}$ of each primer, $2 \mathrm{U}$ of HotStar Taq DNA polymerase (Qiagen), and $0.5 \mu \mathrm{g}$ of DNA. The mixture was subjected to 38 cycles of amplification. After incubation at $95^{\circ} \mathrm{C}$ for $15 \mathrm{~min}$, each cycle consisted of denaturation at $94^{\circ} \mathrm{C}$ for $1.5 \mathrm{~min}$, annealing at $59^{\circ} \mathrm{C}$ for $1.5 \mathrm{~min}$, and elongation at $72^{\circ} \mathrm{C}$ for $3 \mathrm{~min}$. The last cycle was followed by a 5-min elongation step at $72{ }^{\circ} \mathrm{C}$. Amplification of a 297 base pair (bp) sequence of the $\beta$-actin gene was performed in all cases to confirm that the DNA quality was adequate.

After gel electrophoresis and ethidium bromide staining, the rearranged bands were excised and purified using a QIAquick Gel Extraction Kit (Qiagen) according to the manufacturer's instructions. In four cases (cases 1, 3, 4, and 5) the purified PCR products were sequenced directly using both the $3^{\prime}$ and $5^{\prime}$ PCR primers. In case 2, the PCR products were cloned into a pGEM-T vector (Promega, Madison, WI, USA), and plasmids were isolated from 12 randomly selected bacterial colonies (JM109, Promega). Plasmid DNA was purified using the QIAprep miniprep kit (Qiagen) and sequenced using SP6 and T7 primers. DNA sequence analysis using the fluorescence dye terminator method was performed by SeqWright DNA Technology Services (Houston, TX, USA) or The University of Texas MD Anderson Cancer Center DNA Core Analysis Facility (Houston, TX, USA).

The National Center for Biotechnology Information BLAST (Basic Local Alignment Search Tool, National Institutes of Health, Bethesda, MD, USA) software was used to compare the sequence homology of the PCR products within each pair. In order to determine the level of somatic hypermutation of the IgH gene variable $\left(\operatorname{IgV}_{H}\right)$ regions, patients' sequences were aligned to the germline sequences listed in the V-BASE database and assessed as described previously. ${ }^{14}$ Cases were designated as unmutated if there were $2 \%$ or fewer mutations, or mutated if there were more than $2 \%$ mutations, compared with germline sequences. ${ }^{15}$ 


\section{Results}

\section{Clinical and Histologic Findings}

The clinical features of the five patients are summarized in Table 1 . There were two men and three women, with a median age of 65 years (range, 34-70) at the time of diagnosis of typical MCL. The interval between the typical and subsequent blastoid MCL was 11-103 months (median 36). All patients presented with typical MCL in lymph nodes, and four had bone marrow involvement at the time of diagnosis (cases 1, 2, 4, and 5). Subsequent specimens of blastoid MCL involved soft tissue of thigh (cases 3 and 5), lymph node (case 4), ileum (case 2), and rectum (case 1). Patient 2 initially had typical MCL in lymph node, and subsequently developed both typical and blastoid MCL in the ileum 103 months later.

In all cases, the initial lymph node biopsy specimens showed typical MCL. The architecture was effaced by a monotonous proliferation of small to medium-sized lymphoid cells with oval to slightly irregular nuclear contours, moderately dispersed chromatin, generally inconspicuous nucleoli, and scant cytoplasm; the growth patterns were diffuse
(Figures 1a and c and 2a). Mitotic figures were infrequent, with fewer than 10 (range 1-9, median 4) per $10 \times 400$ high-power fields (Table 2). Staining with antibody to Ki-67 demonstrated a median proliferative fraction of $20 \%$ (range 10-50\%) (Figures 1b and 2c, Table 2). In the subsequent biopsy specimens involved by blastoid MCL, four tumors showed a diffuse growth pattern (cases 1, 3, 4 , and 5), and one showed nodular and diffuse growth patterns (case 2). Three cases (cases 1, 4, and 5 ) showed classic blastoid cytology (Figure 2b) and two cases (cases 2 and 3 ) showed pleomorphic cytology (Figure 1d). In the blastoid tumors the mitotic rates ranged from 16-78 (median 48) per $10 \times 400$ high-power fields (Table 2). Staining with antibody to Ki-67 demonstrated proliferative fractions that ranged from 60 to $90 \%$ (median $70 \%$ ) (Figures $1 \mathrm{~b}$ and $2 \mathrm{~d}$, Table 2).

\section{Immunophenotypic Findings}

The immunophenotypes of the typical and blastoid MCL are summarized in Table 2. In all cases, both tumors expressed CD19, CD20, cyclin D1 (nuclear staining) and monotypic surface immunoglobulin

Table 1 Clinical features

\begin{tabular}{|c|c|c|c|c|c|}
\hline Patient & 1 & 2 & 3 & 4 & 5 \\
\hline Age/Gender & $65 / F$ & $34 / \mathrm{M}$ & $65 / \mathrm{M}$ & $64 / F$ & $70 / \mathrm{F}$ \\
\hline \multicolumn{6}{|l|}{ Typical MCL } \\
\hline Presenting site & Lymph node & Lymph node & Lymph node & Lymph node & Lymph node \\
\hline Bone marrow & + & + & - & + & + \\
\hline Lymphadenopathy & + & + & - & + & - \\
\hline Splenomegaly & - & - & - & - & - \\
\hline WBC $(\mathrm{k} / \mu \mathrm{l})$ & 9.8 & 18.7 & 12.9 & 4.7 & 4.8 \\
\hline Lymphocytes $(\mathrm{k} / \mu \mathrm{l})$ & 7.6 & 10.1 & 3.3 & 0.6 & 1.4 \\
\hline Hemoglobin (g/dl) & 13.2 & 15.4 & 11.8 & 12.7 & 12.5 \\
\hline Platelets $(\mathrm{k} / \mu \mathrm{l})$ & 150 & 265 & 218 & 157 & 290 \\
\hline \multirow[t]{2}{*}{ Chemotherapy } & Hyper-CVAD & FC & R-CHOP & Hyper-CVAD & CHOP \\
\hline & FCR & & & $\mathrm{R}$ & \\
\hline \multicolumn{6}{|l|}{ Blastoid MCL } \\
\hline Interval (months) & 66 & 103 & 11 & 36 & 32 \\
\hline Presenting site & Rectum & Ileum & Soft tissue & Lymph node & Soft tissue \\
\hline Morphology & Classic & Pleomorphic & Pleomorphic & Classic & Classic \\
\hline Bone marrow & - & + & NA & NA & NA \\
\hline Lymphadenopathy & + & + & + & + & + \\
\hline Splenomegaly & - & - & - & - & NA \\
\hline WBC $(\mathrm{k} / \mu \mathrm{l})$ & 2.6 & 61.6 & 8.1 & 4.2 & NA \\
\hline Lymphocytes $(\mathrm{k} / \mu \mathrm{l})$ & 0.9 & 42.5 & 1.8 & 0.8 & NA \\
\hline Hemoglobin (g/dl) & 10.6 & 11.0 & 13.0 & 13.0 & NA \\
\hline Platelets $(\mathrm{k} / \mu \mathrm{l})$ & 91 & 312 & 204 & 159 & NA \\
\hline \multirow[t]{2}{*}{ Chemotherapy } & $\mathrm{R}$ & Hyper-CVAD & R, FND & Hyper-CVAD & ESHAP \\
\hline & & $\mathrm{R}^{21}$ & & $\mathrm{R}$ & \\
\hline $\mathrm{BMT}$ & No & Yes & No & Yes & No \\
\hline Follow-up (months) ${ }^{\mathrm{a}}$ & 75 & 142 & 21 & 78 & 72 \\
\hline Outcome & DOD & Remission & DOD & Remission & DOD \\
\hline
\end{tabular}

F, female; M, male; MCL, mantle cell lymphoma; Hyper-CVAD, cyclophosphamide, vincristine, doxorubicin, dexamethasone; FCR, fludarabine, cyclophosphamide, rituxan; R, rituxan; CHOP, cyclophosphamide, doxorubicin, vincristine, prednisolone; FND, fludarabine, mitoxantrone, dexamethasone; ESHAP, etoposide, methylprednisolone, cytarabine, cisplatin; BMT, bone marrow transplantation; NA, not available; DOD, died of disease.

${ }^{\mathrm{a}}$ Follow-up: months from initial diagnosis to last time the patient presented to our institution. 

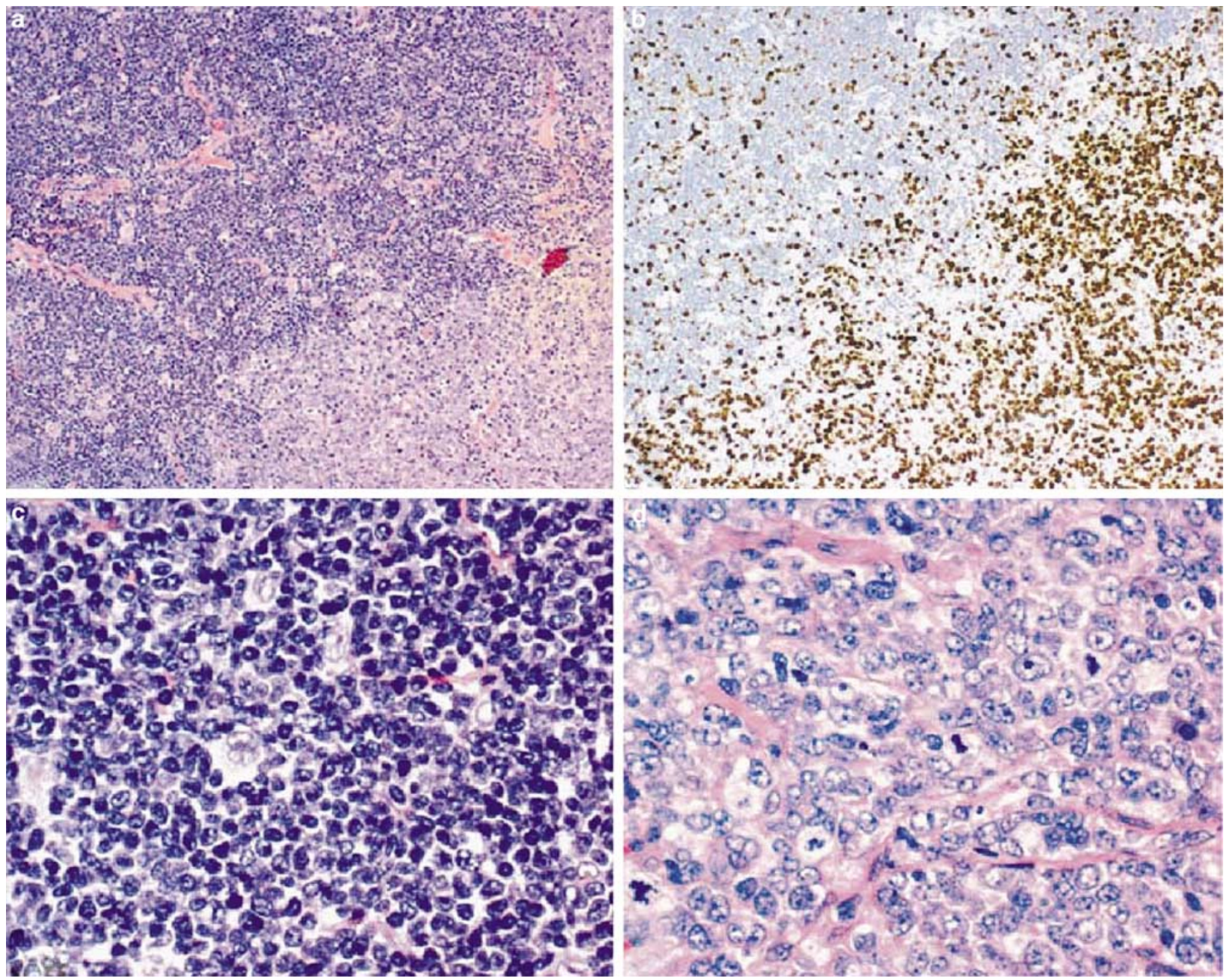

Figure 1 Morphologic features of typical and blastoid MCL involving the same site, ileum, in patient 2. (a) Typical MCL (upper left) and blastoid MCL (lower right) (H\&E, × 200); (b) staining with antibody to Ki-67 (same field as a) (IHC, × 200); (c) typical component $(\mathrm{H} \& \mathrm{E}, \times 400)$; (d) blastoid component $(\mathrm{H} \& \mathrm{E}, \times 400)$.

light chain (four kappa, one lambda), and were negative for CD23. CD5 was positive in all typical MCL. Only three blastoid MCL were CD5 positive. Cases 2 and 3 lost CD5 expression, one of which (case 3) aberrantly expressed CD10.

\section{Sequence Analysis of the IgH Genes}

In order to assess the clonal relationship between the typical and blastoid MCL, we compared the VDJ sequences of the rearranged IgH gene of paired samples from all five patients (Table 3). Clonal rearrangement of the IgH gene was detected in all five tumor pairs, and the VDJ sequences were identical in each pair of cases. In case 2, three identical clones were found in both the typical and blastoid MCL. We assessed the somatic hypermutation status of all cases by comparing the sequences of the $\operatorname{IgV}_{\mathrm{H}}$ region sequences with the germline sequences. Two cases (cases 1 and 3) were unmu- tated; three cases (cases 2, 4, and 5) were mutated (Table 3).

\section{Discussion}

MCL is a distinct type of B-cell non-Hodgkin lymphoma characterized by the $t(11 ; 14)(q 13 ; q 32)$ and cyclin D1 overexpression. Most cases of MCL are composed of a monotonous proliferation of small lymphoid cells, referred to as typical MCL. In contrast, blastoid variants of MCL are histologically more aggressive, but have similar immunophenotypic features and also carry the $\mathrm{t}(11 ; 14)$. Blastoid MCL may arise de novo or in patients with an established diagnosis of typical MCL. In the literature, $10-30 \%$ of patients with typical MCL subsequently develop blastoid variant MCL. ${ }^{3-6}$ It seems reasonable to assume that blastoid MCL represents histologic transformation of typical MCL. However, as this is not the case in patients with Richter's 

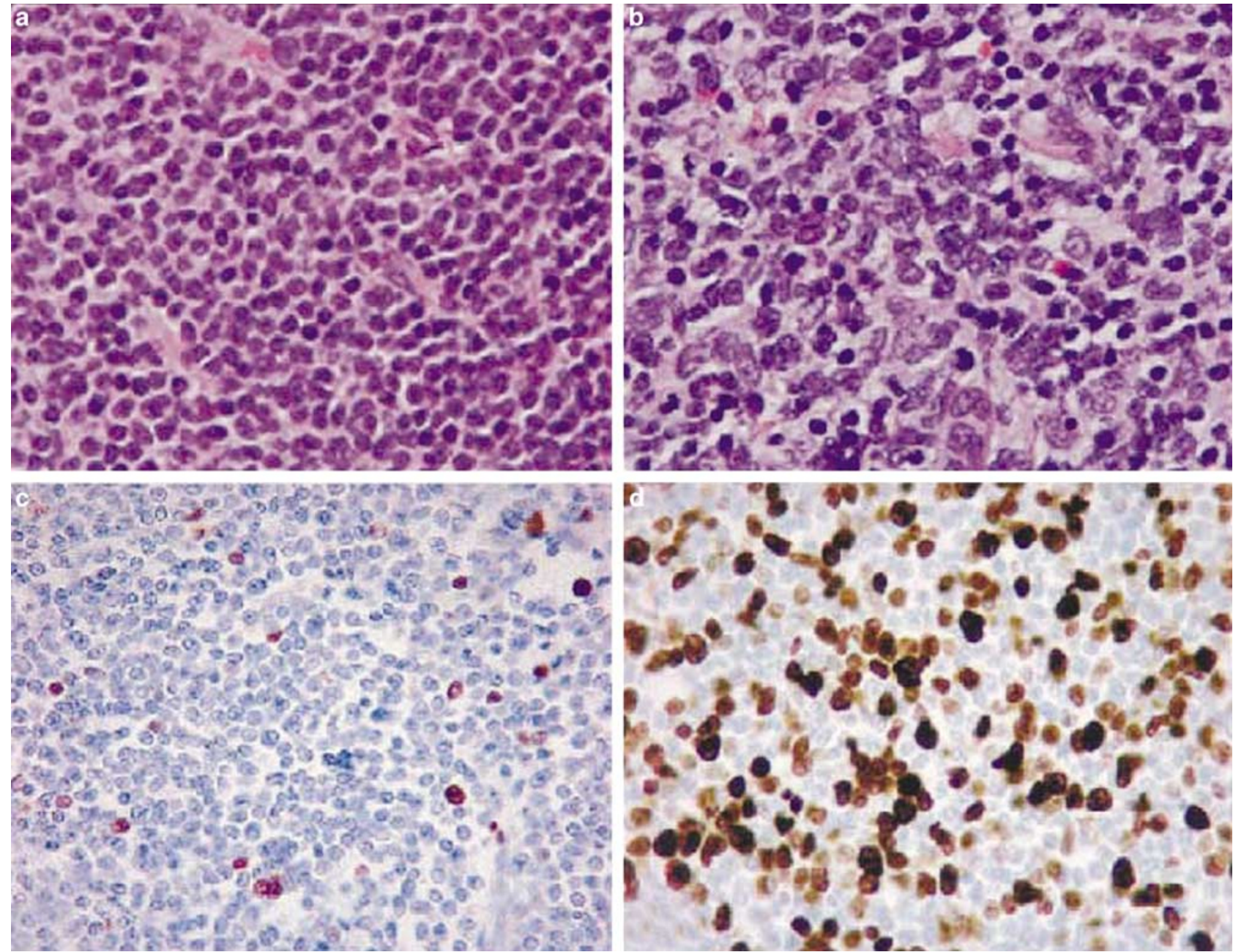

Figure 2 Morphologic features of case 4, with typical (a, c) and pleomorphic blastoid (b, d) MCL. Immunohistochemical stain for Ki-67 demonstrates the lower proliferative fraction in the typical (c) compared to the blastoid $(\mathbf{d})$ component $(\times 400)$.

Table 2 Immunophenotypic features and proliferative fraction

\begin{tabular}{|c|c|c|c|c|c|c|c|c|c|c|}
\hline Case & Туре & CD5 & CD10 & CD19 & CD20 & $C D 23$ & $\kappa / \lambda$ & Cyclin D1 & Ki-67 (\%) & Mitotic index $x^{\mathrm{a}}$ \\
\hline \multirow[t]{2}{*}{1} & Typical & + & - & + & + & - & $\kappa$ & + & 20 & 4 \\
\hline & Blastoid & + & NA & NA & + & NA & $\kappa$ & + & 60 & 16 \\
\hline \multirow[t]{2}{*}{2} & Typical & + & - & + & + & - & $\kappa$ & + & 20 & 9 \\
\hline & Blastoid & - & - & + & + & - & $\kappa$ & + & 90 & 78 \\
\hline \multirow[t]{2}{*}{3} & Typical & + & - & NA & + & NA & $\kappa$ & + & 30 & 1 \\
\hline & Blastoid & - & + & + & + & - & $\kappa$ & + & 90 & 64 \\
\hline \multirow[t]{2}{*}{4} & Typical & + & - & + & + & - & $\kappa$ & + & 10 & 2 \\
\hline & Blastoid & + & - & + & + & - & $\kappa$ & + & 60 & 17 \\
\hline \multirow[t]{2}{*}{5} & Typical & + & - & + & + & - & $\lambda$ & + & 50 & 8 \\
\hline & Blastoid & + & - & + & + & - & $\lambda$ & + & 70 & 48 \\
\hline
\end{tabular}

NA, not available.

${ }^{\mathrm{a}}$ The mitotic index is the number of mitotic figures per $10 \times 400$ high-power fields.

syndrome, in which the CLL/SLL and diffuse large B-cell components are clonally related in only $50 \%$ of patients, ${ }^{7,8}$ there is precedent for hypothesis that typical and blastoid MCL are not clonally related. Hence, we studied at the molecular level five patients with typical MCL who subsequently developed blastoid MCL.

Sequence analysis of the VDJ region of the immunoglobulin heavy-chain genes has proven to be a valuable tool to assess the clonality of B-cell 
Table 3 DNA sequence analysis

\begin{tabular}{|c|c|c|c|}
\hline Case & Type & CDRIII sequence & Mutation rate $(\%)$ \\
\hline \multirow[t]{2}{*}{1} & Typical & GTGCGACGGGCCTCAGCCCGCGGGGCGGGAGCTACA-JH5 & 1.7 \\
\hline & Blastoid & GTGCGACGGGCCTCAGCCCGCGGGGCGGGAGCTACA-JH5 & 1.7 \\
\hline \multirow[t]{6}{*}{2} & Typical & GTACCACATCCCATTACTATGGTTCGGGGAGTTACCCTTTT-JH4 & 6.0 \\
\hline & Blastoid & GTACCACATCCCATTACTATGGTTCGGGGAGTTACCСTTTT-JH4 & 6.0 \\
\hline & Typical & GTGCGACGGGCCTCAGCCCGCGGGGCGGGAGCTACA-JH5 & 5.0 \\
\hline & Blastoid & GTGCGACGGGCCTCAGCCCGCGGGGCGGGAGCTACA-JH5 & 5.0 \\
\hline & Typical & GTGCGAGAGGCGAAGTGGGAGCTACTACATCGGC-JH6 & 11.0 \\
\hline & Blastoid & GTGCGAGAGGCGAAGTGGGAGCTACTACATCGGC-JH6 & 11.0 \\
\hline \multirow[t]{2}{*}{3} & Typical & GTACCACATCCСATTACTATGGTTCGGGGAGTTACССТTTT-JH4 & 1.6 \\
\hline & Blastoid & GTACCACATCCCATTACTATGGTTCGGGGAGTTACCCTTTT-JH4 & 1.6 \\
\hline \multirow[t]{2}{*}{4} & Typical & GTGCAAAAGTGGCTGGTACAACCGAAAACTACTTT-JH4 & 2.2 \\
\hline & Blastoid & GTGCAAAAGTGGCTGGTACAACCGAAAACTACTTT-JH4 & 2.2 \\
\hline \multirow[t]{2}{*}{5} & Typical & GTGCGAGAGGCGAAGTGGGAGCTACTACATCGGC-JH6 & 2.7 \\
\hline & Blastoid & GTGCGAGAGGCGAAGTGGGAGCTACTACATCGGC-JH6 & 2.7 \\
\hline
\end{tabular}

In patient 2, both the typical and blastoid MCL involved the ileum at diagnosis of blastoid MCL. Three identical clones were identified in each component.

neoplasms. ${ }^{16}$ Our studies demonstrated that the VDJ sequences were identical within each pair of samples from all five patients. These findings indicate that the blastoid tumors represent histologic progression of the original neoplastic clones, rather than de novo second tumors. We were unable to perform direct sequence analysis of the PCR products in case 2, the case with typical and blastoid MCL at the same site (ileum). In this case, the two components were separated by microdissection of formalin-fixed, paraffin-embedded tissue sections, and sequence analysis was performed on cloned PCR products. Interestingly, we recovered three identical clones from both components, suggesting an oligoclonal pattern. This finding is similar to the previous observations that some lymphoproliferative disorders, especially those associated with autoimmune disease and immunodeficiency, may show an oligoclonal pattern. ${ }^{17}$ However, we cannot exclude the possibility that both components contained a small number of cells of the other component that were not apparent on histologic examination, and that the presence of multiple clones resulted from the mixture of two (or more) clonally unrelated tumors. Unfortunately, insufficient tissue remains for us to perform singlecell sequence analysis, which would address this problem.

Our data are in keeping with the results of two earlier sequencing studies of patients with typical and blastoid MCL that assessed a total of three patients. ${ }^{9,10}$ Combined with the five cases we report, in all patients typical and blastoid MCL have had identical sequences. In aggregate, it appears that typical and blastoid MCL occurring in the same patient are clonally related.

A recent study of 51 MCL cases (38 typical, 13 blastoid) has shown that about $20 \%$ (eight typical, two blastoid) of MCL cases display somatically mutated $\operatorname{IgV}_{\mathrm{H}}$ genes, whereas $80 \%$ are unmutated. ${ }^{18}$ Similarly, Pittaluga et $a l^{19}$ reported that three of nine blastoid MCL had mutated $\operatorname{IgV}_{\mathrm{H}}$ genes. Cogliatti et $a l,{ }^{20}$ in a study of 21 cases of blastoid MCL, found that positive $\operatorname{IgV}_{\mathrm{H}}$ mutational status had no statistically significant prognostic impact on event-free or overall survival. However, in Cogliatti's ${ }^{20}$ study mutated blastoid MCL tended to present more often at an earlier stage and without bone marrow involvement, and to show lower rates of relapse and death, resulting in a more favorable clinical outcome. Similarly, Orchard et $a l^{21}$ found that among 80 MCL patients (72 typical/small MCL and eight blastoid MCL), mutation status did not statistically affect survival. However, five of five long-term survivors (more than 90 months) had mutated $\operatorname{IgV}_{\mathrm{H}}$ genes, suggesting that mutated $\operatorname{IgV}_{\mathrm{H}}$ genes may help identify patients with indolent disease. ${ }^{21}$ Compared to these studies, we found a higher percentage (60\%) of mutated cases. This discrepancy may be due to our referral patient population or to the relatively small size of our series, rather than reflecting the biology of MCL cases that subsequently undergo histologic progression.

Few studies have compared the immunophenotype of paired samples of typical and blastoid MCL. ${ }^{3}$ We performed immunophenotypic analysis of the five paired samples using a combination of immunohistochemical and flow cytometric studies. All samples assessed were positive for CD19, CD20, cyclin D1, and negative for CD23, and all typical cases were positive for CD5. All cases showed the same immunoglobulin light chain within each pair. Interestingly, two blastoid tumors lost CD5 expression, one of which aberrantly expressed CD10. Absence of CD5 expression has been described in up to $10 \%$ of all MCL cases. ${ }^{22}$ However, reports of cases that have converted from a CD5-positive to a CD5-negative immunophenotype, or that show concurrent CD5-positive and CD5-negative tumors at different sites are unusual. ${ }^{23}$ Reports of aberrant CD10 expression by MCL are also rare, and most often associated with blastoid morphology. ${ }^{23,24}$ 
In summary, we have shown that typical and blastoid MCL are clonally related in five patients. These results support the concept that blastoid MCL arising in patients with a history of typical MCL generally represents histologic progression of the original neoplastic clone, rather than a de novo tumor. We also have assessed the mutation status of the IgH genes in these cases and identified immunophenotypic changes associated with blastoid transformation.

\section{References}

1 Lai R, Medeiros LJ. Pathologic diagnosis of mantle cell lymphoma. Clin Lymphoma Myeloma 2000;1:197-206.

2 Swerdlow SH, Williams ME. From centrocytic to mantle cell lymphoma: a clinicopathologic and molecular review of 3 decades. Hum Pathol 2002;33:7-20.

3 Kaleem Z, Wakoff AR, Smith RP, et al. Blastic transformation of mantle cell lymphoma. Arch Pathol Lab Med 1996;120:577-580.

4 Norton AJ, Matthews J, Pappa V, et al. Mantle cell lymphoma: natural history defined in a serially biopsied population over a 20-year period. Ann Oncol 1995;6:249-256.

5 Raty R, Franssila K, Jansson SE, et al. Predicative factors for blastoid transformation in the common variant of mantle cell lymphoma. Eur J Cancer 2003;39:321-329.

6 Tiemann M, Schrader C, Klapper W, et al. Histopathology, cell proliferation indices and clinical outcome in 304 patients with mantle cell lymphoma (MCL): a clinicopathological study from the European MCL Network. Br J Haematol 2005;131:29-38.

7 Muller-Hermelink HK, Montserrat E, Catovsky D, et al. Chronic lymphocytic leukaemia/small lymphocytic lymphoma. In: Jaffe ES, Harris NL, Stein H, Vardiman JW (eds). World Health Organization Classification of Tumours: Pathology and Genetics of Tumours of Haematopoietic and Lymphoid Tissues. IARC Press: Lyon, France, 2001, pp 127-130.

8 Ohno T, Smir BN, Weisenburger DD, et al. Origin of the Hodgkin/Reed-Sternberg cells in chronic lymphocytic leukemia with 'Hodgkin's transformation'. Blood 1998;91:1757-1761.

9 Laszlo T, Matolcsy A. Blastic transformation of mantle cell lymphoma: genetic evidence for a clonal link between the two stages of the tumour. Histopathology 1999;35:355-359.

10 Pott C, Schrader C, Bruggemann M, et al. Blastoid variant of mantle cell lymphoma: late progression from classical mantle cell lymphoma and quantitation of minimal residual disease. Eur J Haematol 2005;74: 353-358.
11 Swerdlow SH, Berger F, Isaacson PI, et al. Mantle cell lymphoma. In: Jaffe ES, Harris NL, Stein H, Vardiman JW (eds). World Health Organization Classification of Tumours: Pathology and Genetics of Tumours of Haematopoietic and Lymphoid Tissues. IARC Press: Lyon, France, 2001, pp 168-170.

12 Yin CC, Lin P, Carney DA, et al. Chronic lymphocytic leukemia/small lymphocytic lymphoma associated with IgM paraprotein. Am J Clin Pathol 2005;123: 594-602.

13 Abruzzo LV, Rosales CM, Medeiros LJ, et al. Epstein-Barr virus-positive B-cell lymphoproliferative disorders arising in immunodeficient patients previously treated with fludarabine for low-grade B-cell neoplasms. Am J Surg Pathol 2002;26:630-636.

14 McCarthy $\mathrm{H}$, Wierda WG, Barron LL, et al. High expression of activation-induced cytiding deaminase (AID) and splice variants is a distinctive feature of poor-prognosis chronic lymphocytic leukemia. Blood 2003;101:4903-4908.

15 Hamblin TJ, Davis Z, Gardiner A, et al. Unmutated $\operatorname{IgV}(\mathrm{H})$ genes are associated with a more aggressive form of chronic lymphocytic leukemia. Blood 1999;94:1848-1854.

16 Diss TC, Pan L. Polymerase chain reaction in the assessment of lymphomas. Cancer Surv 1997;30: 21-44.

17 Dolcetti R, Boiocchi M. Cellular and molecular bases of B-cell clonal expansions. Clin Exp Rheumatol 1996; (Suppl 14):S3-S13.

18 Thorselius M, Walsh S, Eriksson I, et al. Somatic hypermutation and $\mathrm{V}(\mathrm{H})$ gene usage in mantle cell lymphoma. Eur J Haematol 2002;68:217-224.

19 Pittaluga S, Tierens A, Pinyol M, et al. Blastic variant of mantle cell lymphoma shows a heterogenous pattern of somatic mutations of the rearranged immunoglobulin heavy chain variable genes. $\mathrm{Br} J$ Haematol 1998;102:1301-1306.

20 Cogliatti SB, Bertoni F, Zimmermann DR, et al. IgV H mutations in blastoid mantle cell lymphoma characterize a subgroup with a tendency to more favourable clinical outcome. J Pathol 2005;206:320-327.

21 Orchard J, Garand R, Davis Z, et al. A subset of $\mathrm{t}(11 ; 14)$ lymphoma with mantle cell features displays mutated $\operatorname{IgV}_{\mathrm{H}}$ genes and includes patients with good prognosis, nonnodal disease. Blood 2003;101: 4975-4981.

22 Liu Z, Dong HY, Gorczyca W, et al. CD5- mantle cell lymphoma. Am J Clin Pathol 2002;118:216-224.

23 Morice WG, Hodnefield JM, Kurtin PJ, et al. An unusual case of leukemic mantle cell lymphoma with a blastoid component showing loss of CD5 and aberrant expression of CD10. Am J Clin Pathol 2004;122:122-127.

24 Dong HY, Gorczyca W, Liu Z, et al. B-cell lymphomas with coexpression of CD5 and CD10. Am J Clin Pathol 2003;119:218-230. 